ISAHP 2005, Honolulu, Hawaii, July 8-10, 2005

\title{
RURAL WATER SUPPLY AND SANITATION IN DEVELOPING COUNTRIES
}

\author{
Shashi Bhattarai \\ Integrated Consultants Nepal (ICON) \\ P O Box 3839, Baneswor Heights, Kathmandu, Nepal \\ shashi@icon.com.np \\ Markus Starkl \\ University of Natural Resources and Applied Life Sciences, Vienna \\ Department for Water, Atmosphere and Environment \\ markus.starkl@boku.ac.at
}

Keywords: Developing Countries, Decision Making, Rural Water Supply and Sanitation, Sustainability assessment, Benchmarking

Summary: The appropriateness of the application of AHP in rural water supply and sanitation (RWSS) projects in developing countries, with the growing need for, and application of, Multi Criteria Analysis (MCA) techniques for integrated approach is discussed.

Two application scenarios are presented in the paper, taken from consulting assignments in Nepal, where the consultants used conventional methods. This paper has been prepared in order to raise awareness among the consulting community as well as RWSS planners and managers about the availability of the AHP tool as well as to demonstrate the power of the tool in planning, management, sustainability assessment and benchmarking of RWSS in developing countries.

The processes of social learning and decision-making increasingly demand an integrated approach to handle the information, which is generated, perhaps for planning and management of new projects, for sustainability assessment or for benchmarking of completed projects. Among various tools assessed, the AHP-based MCA tool is a promising one. The paper, with brief literature review, concludes with recommendations on further research, study and action required on the application of AHP for RWSS system analysis in developing countries.

\section{Introduction}

The Water Supply and Sanitation (WATSAN) planning, implementation, management and sustainability assessment process needs to address social justice, economic equity and environmental and financial sustainability issues with appropriate technology. Additionally, people-focused WATSAN systems may face different, conflicting factors, because they need to satisfy different categories of stakeholders (communities including women, children and other water-users with diverse, ethnic, economic, educational, cultural and religious characteristics; foreign and local investors; local and central government; service providers; politicians; advocates and so on).

The process of WATSAN planning and management demands justifiable, equitable, sustainable, appropriate and consensus-based solutions for all stakeholders simultaneously. The WATSAN system involves decision-making at various stages and demands a balanced and in-depth analysis of decisions, covering subjective and objective factors addressing the issues that concern all stakeholders. Much progress has been made on information generation at community level; however, there is still a requirement for processes or tools to properly synthesize the generated information in order to arrive at rational and sustainable development decisions. 
There has been extensive research, development and application work in this field, including Participatory Rural Appraisal (PRA), Rapid Rural Appraisal (RRA), Participatory Learning and Action (PLA) Initiative, Methodology for Participatory Assessment (MPA), NEWAH Participatory Assessment (NPA) and so on. In line with PRA and RRA; PLA and MPA method originally designed by IRC and The World Bank. NPA is a modified version of MPA developed by Nepal Water for Health (NEWAH) specifically for Nepalese applications. All the methods generate massive amounts of information but unfortunately there is lack of an appropriate tool for assembling the information for integrated assessment and interpretation. It is obvious that the more information is generated, the greater becomes the challenge to assess and process it. This demands powerful integrated decision aid techniques, like Multi Criteria Analysis (MCA) tools. After all, the ultimate objective of obtaining varied information at different levels is to deliver the most rational decision.

The objective of this Paper is to draw attention to the need for MCA techniques in WATSAN planning, management and sustainability assessment. The Paper observes that a criteria-based decision-making system, as recommended by the consultant in the first scenario below - Community Based Water Supply and Sanitation Sector Project (CBWSSP) - is necessary but not sufficient. Similarly, in the second scenario discussed below - relating to sustainability assessment - AHP-based tools could have provided integrated insight into the sustainability assessment of completed RWSS schemes, if these had been used by the consultant. After a brief literature review, the Paper concludes with recommendation on further research, study and action needed on WATSAN system planning and management in developing countries.

\section{Multi Criteria Analysis (MCA)}

MCA is a process of integrated assessment of alternatives or options for setting, ranking or selecting priorities from a finite set of alternatives. MCA-based approaches make the options and their contribution to the different criteria open, and all require the exercise of judgment. MCA processes are gaining in popularity because of their ability to integrate assessment of subjective and objective information with stakeholders' values, in a single framework. MCA is a structured approach to determine overall preferences among alternative options, where the options accomplish several objectives.

There exist many MCA-based approaches such as Analytic Hierarchy Process (Saaty, 1980), MultiAttribute Utility Theory (MAUT), Simple Multi-Attribute Rating Technique (SMART), Preference Ranking Organization Method for Enrichment Evaluations (PROMETHEE), Elimination and Choice Translating Reality (ELECTRE), Novel Approach for Imprecise Assessment and Decision Evaluations (NAIADE) etc. However the use of MCA-based approaches in system planning, management and sustainability assessment in WATSAN projects in a variety of situations and countries is still an underresearched area.

The application of MCA tools is still rare among practicing WATSAN professionals, with a few notable exceptions e.g. Bhattarai and Neupane (2001). Even now related literature is mostly based on academic work (e.g. Kholghi, 2001; Moeffart, 2003; Anagnostopolos et al., 2003 and Marciano et al., 2003). This reflects the fact that civil engineers - the major players in WATSAN sector - started interacting on decision-making aspects only recently (Bhattarai, 2002).

\subsection{Sustainability, Decision Making and MCA in RWSS}

The use of integrated analysis in sustainability assessments is now increasingly seen as important in developing new processes. Integration of communities, institutions and policy-makers with demand, gender and poverty for sustainability is focused on MPA method and a process has been developed by Dayal et al. (2000). While addressing sustainability and equity holistically in WATSAN systems, the need for integration of social, financial, technical, environmental and institutional factors is wellappraised in Mukherjee, 2003. Utilization of multi-dimensional indicators, consensus-building and 
benchmarking as demonstrated in MPA (Dayal, et al., 2000; Mukherjee, 2003) are a kind of MultiCriteria Analysis (MCA) exercise. Sustainable WATSAN systems demand the use of MCA-based tools, and MPA understood the need for MCA and developed an improved process of information collection (improved PRA) and also a process of integration.

It is worthwhile to cite here the recent work on Social Multi-Criteria Evaluation (SMCE) by Munda (2004) and share his conclusion from his case studies, one among five: "The combination of various participatory methods, which have been proved powerful in sociological research, becomes even more so when integrated with a multi-criterion framework" (Munda, 2004). It has also been observed that utilization of an MCA tool such as Analytic Hierarchy Process (AHP) could facilitate a holistic approach to sustainable planning and management of people-centered WATSAN systems in developing countries (e.g. Starkl et al., 2003). The appropriateness of AHP-based MCA for participatory decision-making is also presented in Schmoldt (1994).

However, despite the potential of MCA for supporting decision-making processes, several challenges have to be taken into account as well. Brunner and Starkl (2004), for example, have made a critical survey on decision aid systems for evaluating sustainability.

Future decision-making processes in the WATSAN sector, which will result in the implementation of a certain system, will have to take into account the dilemma of feasibility vs. sustainability. In practice there is pressure on economic aspects of such systems, which may dominate other relevant intangible aspects. This observation has recently been confirmed by Acreman (2003). Nevertheless, aiming at integrated and participatory water management requires new tools for decision-making. MCA tools may have some potential in this context.

\section{First Scenario: The Community Based Water Supply and Sanitation Project (CBWSSP)}

The Community Based Water Supply and Sanitation Project (CBWSSP) is part of Project Preparation Technical Assistance (PPTA NO. 3844 NEP) to His Majesty's Government of Nepal (HMG/N) with support from the Asian Development Bank. The project focuses on providing rural water supply and sanitation (RWSS) facilities and services to improve community health and provide opportunities for income generation. The aim of the project is to provide improved RWSS services to about 1,200 rural communities in 20 of the 75 Districts in Nepal (CBWSSP PPTA, 2003). In total the project will address the needs of about 850,000 people - around $15 \%$ of the unserved population of Nepal.

\subsection{Decision Making Aspects in CBWSSP}

There are two staged decisions proposed in CBWSSP: selection of Districts, and selection of communities within a District. There are very large unserved or under-served people in communities who would benefit from the delivery of improved water and sanitation services. At the same time there are serious physical, financial, and human resource constraints that limit how widely and how quickly improved facilities and services can be made available to all the communities needing them. This simple fact necessitates prioritizing deserving communities in need of improved facilities, a process which requires the use of critical decision-making exercises.

The same applies to Districts where historical inequities exist in the provision of government and donorfinanced facilities and services. These inequities have resulted in, for example, relatively high levels of water and sanitation in certain Districts, and low levels in others. To rectify these inequities it is necessary to go beyond politically motivated decision-making and focus on limited sectoral resources in Districts that are in the worst condition.

\subsection{District Selection Decision}


District-level data, prepared by the PPTA through Geographical Information System (GIS) analysis and other sources, is used to rank Districts using different kind of criteria. CBWSSP GIS maps with criteria to illustrate the ranking of districts are recommended for the purpose of allocating available financial resources. Until additional financial resources become available, realistic decisions must focus on meeting the needs of some Districts and not others. District prioritization criteria included in the CBWSSP GIS is presented in Table 1.

The recommended method on the CBWSSP PPTA covered six factors (Table 1) in the GIS maps of districts. The six factors selected are mutually conflicting in nature. For example, Districts with higher HDI, low water supply and sanitation coverage and high incidence of diseases may have a low percentage of Dalits (disadvantaged group of people). On top of the conflicting nature of objectives, the weighting of factors varied among the different decision-makers or stakeholders. The ranking of District varies if the weighting of factors or the importance of factors changes. The CBWSSP GIS-based District ranking recommendation is silent about its sensitivity to the relative weight of different factors. District selection decision-making (spatial decision-making) must cater for multiple socio-economic factors as well as the physical condition of Districts (water supply coverage). Traditional decision-support techniques lack the ability to integrate and weight conflicting factor, while GIS, although recognized as a useful decision-support technology, does not provide the means to handle multiple decision factors (Jun, 2000).

A framework for the integration of GIS and AHP-based MCA systems for prioritizing Districts/sites is presented as intelligent geographic information system for-multi criteria selection in paper by Jun, 2000, addressing the gap seen in CBWSSP District selection decision-making approach recommended.

Table 1. GIS District Selection Criteria

\begin{tabular}{|l|l|}
\hline \multicolumn{1}{|c|}{ Factors } & \multicolumn{1}{c|}{ Criteria } \\
\hline Human Development Index (HDI) & $\begin{array}{l}\text { Only Districts with HDI of 0.330 or less will qualify for initial } \\
\text { assistance }\end{array}$ \\
\hline Water Supply Coverage & Districts with water supply coverage of 60 percent or less \\
\hline Sanitation (Latrine) Coverage & Districts with improved latrine coverage of 50 percent or less \\
\hline Incidence of Diarrhoeal Disease & $\begin{array}{l}\text { Districts with incidence of Diarrhoeal disease rate of say, more } \\
\text { than 0.1 per 1,000 }\end{array}$ \\
\hline Historically Underserved Areas & Locations more than 20 km from the nearest improved road \\
\hline Percentage of Dalits and others & $\begin{array}{l}\text { Districts with certain percentage of Dalit / ethnic and indigenous } \\
\text { group of population }\end{array}$ \\
\hline
\end{tabular}

Source: CBWSSP PPTA (2003)

\subsection{Community or Scheme selection}

Prospective communities (or schemes) are to be prioritized according to hardship factors, a clear willingness to share the costs of water supply planning and development, and social and poverty factors (Table 2). All schemes selected must have already been identified and prioritized in the District Development Plan.

It can be observed that the objective of these factors and sub-factors are mutually conflicting and the importance or preference of various factors and sub-factors to stakeholders have not been considered in CBWSSP recommendation.

In any real-life decision problem, decision-making factors conflict in nature and require 'trade-offs', that is to say, people prefer schemes at the highest hardship location and at the lowest community contribution: however the choice of the scheme depends upon the preference or weight given to each factor. For example, if local government is looking for most-hardship schemes, they have to trade-off with higher price or more community contribution. 
CBWSSP had recommended a ten-factor community selection/prioritization criteria to use in the selection decision. However, NPA-based Socio-Economic Survey (SES) of a selected community conducted by the project on fifteen categories of information headings generated around one hundred sub-categories of information at each community (CBWSSP PPTA, 2003). As stated earlier, the lack of appropriate tools for the integrated analysis of gathered information in order to prioritize communities is evident, and this is a critical aspect of CBWSSP preparatory tasks. However, the CBWSSP preparation report is, unfortunately, silent on this.

Table 2. Scheme Selection Decision Criteria

\begin{tabular}{|l|l|l|}
\hline \multicolumn{1}{|c|}{ Hardship Factors } & \multicolumn{1}{|c|}{ Willingness to Share Costs } & \multicolumn{1}{|c|}{ Social and Poverty Factors } \\
\hline $\begin{array}{l}\text { Time for fetching water is } \\
\text { more than } 30 \text { minutes per } \\
\text { round trip }\end{array}$ & $\begin{array}{l}\text { At least } 20 \% \text { community } \\
\text { contribution, with }>1 \% \text { in cash. }\end{array}$ & $\begin{array}{l}\text { Households having food } \\
\text { sufficiency for less than six } \\
\text { months in a year. }\end{array}$ \\
\hline $\begin{array}{l}\text { Existing accessible water } \\
\text { sources are available less than } \\
9 \text { months per year. }\end{array}$ & $\begin{array}{l}\text { For poor communities in remote } \\
\text { inaccessible areas the minimum } \\
\text { contribution will be reduced to } \\
\text { 10\%, although per capita cost } \\
\text { might be higher. }\end{array}$ & $\begin{array}{l}\text { Households whose major source } \\
\text { of income is wage labor. }\end{array}$ \\
\cline { 1 - 1 } Water Quality & $\begin{array}{l}\text { Female headed households \& } \\
\text { households with disabled persons. }\end{array}$ \\
$\begin{array}{l}\text { Quantity - Whether average } \\
\text { per capita }\end{array}$ & $\begin{array}{l}\text { Other criteria including literacy, } \\
\text { health indicators, etc. }\end{array}$ \\
\hline
\end{tabular}

Source: CBWSSP PPTA (2003)

\subsection{First Scenario Conclusion}

The application of Analytic Hierarchy Process (AHP)-based MCA tools can be observed in a two-step procedure for selecting projects in the Third Community Support Program (TCSP) in Greece by Anagrostopoules et al. (2003). The two-step MCA procedure utilized for determining priorities among Prefectures (Districts) and prioritizing the large number of projects / schemes within the priority Prefectures was used to overcome the empirical rules and political considerations traditionally dominating the selection of projects and financial resource allocation for TCSP in Greece. The AHP-based MCA process was a good demonstration of the kind of decision-making process needed in District and Community level prioritizing / selection process in CBWSSP in Nepal.

\section{Second Scenario: Sustainability Assessment of Operating RWSS}

The Rural Water Supply and Sanitation Fund Development Board (RWSSFDB) is financing communitybased demand-driven rural water supply and sanitation (RWSS) projects through the help of local nongovernmental organizations, called Support Organizations (SO) in Nepal. The RWSSFDB appointed a local consulting company (CMS/ICON, 2004) to carry out a sustainability assessment study of 44 schemes from 203 RWSS schemes implemented in 24 Districts during the RWSSFDB Batch II project period (1998-2000). From this work, in addition to a sustainability assessment, the government of Nepal as well as RWSSFDB expected useful inputs in policy issues and guidelines for further improvements in the water supply and sanitation service delivery in the rural areas of Nepal.

\subsection{Background and Process Used by Local Consultants}

The objectives of the sustainability study were to assess/evaluate the performance of the schemes implemented, to evaluate existing the capabilities of the communities to operate and manage their own physical, financial and institutional assets, to asses the effectiveness of capacity-building approaches, processes and guidelines, and to identify key lessons learnt and specific measures to strengthen the sustainability of the schemes. The study focused on the physical, financial and institutional aspects of the project covering all the major activities under the different phases of RWSS development schemes. 
The study used the conventional approaches of PRA and RRA. The methodology included Desk Study, Preparation of Data Formats and Questionnaires, Identification of Key Informants, Field testing of data formats and questionnaires, Orientation/ Training of field staff, Field survey, Verification of field survey data and Data analysis. The sustainability analysis was grouped into four categories or factors, namely Technical Aspects, Social Aspects, Institutional Aspects and Financial Aspects and sixteen sub-factors associated with these. Each scheme was rated excellent, good or poor on these factors. A database was developed using SPSS package, a statistical and database analytical tool. This tool helped with the development of a database and also helped analyze the available information to produce cross-tables for various parameters and indicators.

The methodology used in the assessment was a kind of multi-criteria analysis but was evaluated in isolation and without integration. The authors reassessed the sustainability using an AHP-based ranking model using the same factors and sub-factors. The AHP-based sustainability assessment also involved an engineer and sociologist who were part of the team conducting the conventional process of sustainability. The AHP-based sustainability assessment is discussed in the following section.

\subsection{Sustainability Assessment and Benchmarking of RWSS using AHP}

A four-level AHP rating model based on the factors used in the conventional method (presented in Table 3) was constructed and the water supply and sanitation engineer and sociologist judged the 44 RWSS schemes based on the field information of each schemes collected using PRA and RRA methods. The same individuals were involved in the assessment conducted by conventional method.

The water supply and sanitation engineer and sociologist made pair-wise comparisons of the factors and sub-factors of the sustainability assessment based on the AHP rating model. The AHP model used is based on the factors and sub-factors presented in Table 3. Likewise, the evaluation of sub-factors was made context-sensitive. For example, in the case of 'Functionality of Tap' the AHP-based approach used 'Excellently functioning', 'Moderately functioning', 'Poorly functioning' or 'Not functioning' instead of Excellent, Good or Poor as used globally in the conventional process of sustainability assessment earlier used by consultant.

The sustainability composite score generated by the AHP rating model distributed the RWSS schemes according to three categories: 'High' with score grater than 0.7 , 'Moderate' with score $0.40-0.70$ and 'Low' with score less than 0.40 . The result was obtained with the consensus of sociologist and engineer involved in the consultant's earlier task. Distribution of RWSS schemes in three categories in both cases are presented in Table 4 . The following Figure 1 gives the sustainability index distribution, which is very useful information for RWSS sustainability benchmarking. 
Table 3. Sustainability Assessment Factors and sub-factors

\begin{tabular}{|c|c|}
\hline Factors/Sub-factors & Description \\
\hline \multicolumn{2}{|l|}{ Institutional } \\
\hline WSUC & $\begin{array}{l}\text { Water and Sanitation Users Committee (WSUC) Existence, } \\
\text { Functionality, Activeness, Ownership and Meeting }\end{array}$ \\
\hline VMW & $\begin{array}{l}\text { Village Maintenance Workers (VMW) Availability, Skill, Training, } \\
\text { Activeness, Continuity and Remuneration }\end{array}$ \\
\hline Treasurer & $\begin{array}{l}\text { Availability, Skill, Training, Activeness, Continuity and Book } \\
\text { keeping }\end{array}$ \\
\hline $\begin{array}{r}\text { Mother \& Child Tap stand } \\
\text { Group (MCTG) }\end{array}$ & Existence, Regular cleaning \& operating of tap, O\&M fund collection \\
\hline $\begin{array}{l}\text { Women Technical Support } \\
\text { Services Group (WTSSG) }\end{array}$ & Income Generating Activities (IGA), Use of WTSS fund in IGA \\
\hline Coordination \& Linkage & With local authorities and other agencies, training, dispute resolution \\
\hline \multicolumn{2}{|l|}{ Social/Environmental } \\
\hline Community Participation & In planning, decision-making, implementation and O\&M \\
\hline Health \& Hygiene & HSE conduction, Latrine coverage, VHP working \\
\hline Environment & Environmental mitigation measures, drainage \\
\hline \multicolumn{2}{|l|}{ Financial } \\
\hline O\&M Fund & Existence, Bank Account, Use of O\&M fund \\
\hline Water Tariff Collection & Regular, Intermittent, As and when needed basis \\
\hline \multicolumn{2}{|l|}{ Technical } \\
\hline $\begin{array}{lr}\text { Source } & \\
& \text { Yield } \\
& \text { Quality }\end{array}$ & $\begin{array}{l}\text { Reliability, Adequacy, Depletion, Continuity, Physical, Biological } \\
\text { and Chemical quality, Accessibility and chances of contamination }\end{array}$ \\
\hline $\begin{array}{r}\text { Design \& Construction } \\
\text { Quality }\end{array}$ & $\begin{array}{l}\text { Design adequacy, Site \& Technology selection, Condition and } \\
\text { functionality of structures and system }\end{array}$ \\
\hline Tap Functioning & Functionality of taps \\
\hline
\end{tabular}

The assessment demonstrated that the sustainability assessment and benchmarking of RWSS schemes using an AHP rating model could deliver insight to the process of developing an integrated framework. The consultant team could visualize the shift of number of schemes from moderate sustainability to low sustainability with use of integrated AHP model with their own judgment. The power of the AHP-based sensitivity analysis in sustainability assessment was fully recognized by the consultant's team who had previously used the conventional process.

Table 4: Comparative Result of Sustainability Status of RWSS Schemes

\begin{tabular}{|c|c|c|}
\hline \multirow{2}{*}{ Sustainability Range } & \multicolumn{2}{|c|}{ Number of RWSS Schemes } \\
\cline { 2 - 3 } & Consultants Approach & AHP Based Rating Result \\
\hline High & 25 & 27 \\
\hline Moderate & 64 & 41 \\
\hline Low & 11 & 32 \\
\hline
\end{tabular}




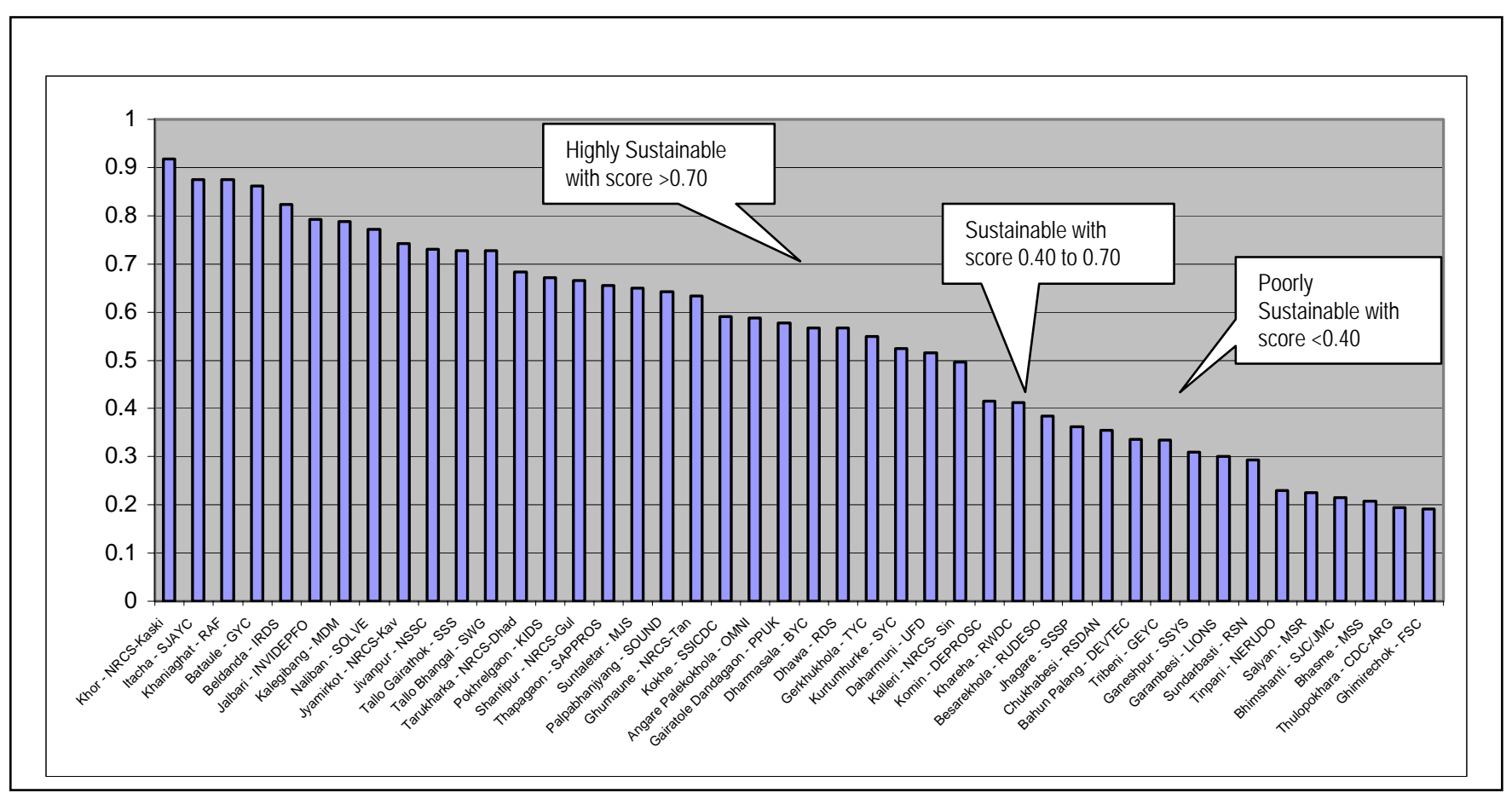

Figure 1: Sustainability Ranking and Benchmarking of Schemes

\section{Concluding Recommendation}

WATSAN system planning, management and sustainability assessment in developing countries needs further research, study and action on the following, in order to address practical problems in their implementation:

- $\quad$ Promotion of the benefits of the integration of generated information from people, to help planners to arrive at rational decisions and sustainability assessments.

- Identification and recommendation of appropriate MCA tools: so far Analytic Hierarchy Process based MCA techniques has emerged as a good option.

- The use of a multidisciplinary professional or MCA expert, who could integrate the input of a variety of different experts such as engineer, sociologist, gender and development specialist, economist, environmentalist and stakeholders, specifically for the development of Decision or Multi-Criteria Analysis and reporting.

\section{References}

Acreman, M. (2003). “Ethical Aspects of Water and Ecosystems”, Water Policy, vol.3, pp257-265.

Anagnostopoulus K. P., M. Gannopoulou, Y. Roukounis and A. Vavatiskos (2003) "A Two-step Procedure for Selecting Projects at Regional Level", Proceedings of 7th International Symposium on Analytic Hierarchy Process (ISAHP 2003), Bali, Indonesia, 111-118. 
Bhattarai, S. (2002), "Advances in Civil Engineering from Decision Making Perspective" in J. N. Bandyopadhyay and D. Nagesh Kumar (ed.), Advances in Civil Engineering, IIT Kharagpur, Allied Publishers, India, 1506 - 1512.

Bhattarai, S. and B. Neupane (2001), “Informed Decision-Making for Drainage Management”, in John Pickford (ed.) Water, Sanitation and Hygiene: Challenges of the Millennium: Proceedings of the 26th WEDC Conference, Loughborough University, UK, 315-318.

Brunner, N. and Starkl, M. (2004), "Decision Aid Systems for Evaluating Sustainability: A Critical Survey” Journal of EIA Review, In press.

CBWSSP PPTA Report (2003) "Nepal Community-Based Water Supply and Sanitation Project Preparation Technical Assistance (TA No. 3844 NEP), Final Report, ARD Inc., USA / CMS Nepal / ICON Nepal.

CMS/ICON (2004) " Sustainability Study of Batch-II Schemes" Consolidated Management System (CMS) in Joint Venture with Integrated Consultants Nepal (ICON), Final Report, Rural Water Supply and Sanitation Fund Development Board (RWSSFDB).

Dayal, R., Christine van Wijk and N. Mukherjee (2000), Methodology for Participatory Assessment, Water and Sanitation Program, The World Bank and International Water and Sanitation Center, Delf, The Neatherlands.

Jun, Chulmin (2000), "Design of an Intelligent Geographic Information System for Multi-criteria Site Analysis”, URISA Journal, Vol. 12, No. 3, pp 6-17.

Kholghi, M. (2001) “Multi-Criterion Decision-Making Tools for Wastewater Planning Management”, Journal of Agricultural Science Technology, 3: 281-286.

Marciano C., T. Calabro, A. I. De Luca (2003), "Achieving A Common Strategy for an Integrated Rural Development Plan in South Italy Using AHP", Proceedings of Intl. Conference on Reinventing Regions in the Global Economy, Organized by Regional Studies Association, Internet: http://www.regionalstudies-assoc.ac.uk/events /120403papers.asp (26-03-2004).

Moeffart, Denis Van (2003) "Multi Criteria Decision Aid in Sustainable Urban Water Management", $M$ Sc Thesis (TRITA-KET-IM 2002:26), Royal Institute of Technology, Dept. of Chem. Engg. and Tech., Division of Industrial Ecology, SE-10044, Stockhome, Swden.

Mukherjee, Nilanjana (2003), "Planning and Monitoring for Sustainability and Equity" in Brain Reed (ed.) Sustainable Environmental Sanitation and Water Services: Proceedings of $28^{\text {th }}$ WEDC Conference, Loughborough University, UK, pp464-467.

Munda, Giuseppe (2004), "Social multi criteria evaluation: Methodological foundation and operational consequences”, European Journal of Operational Research, Vol. 158, Issue 3, pp 662-667.

Saaty, T. L. (1980), The Analytic Hierarchy Process, McGraw - Hill International.

Schmoldt, Daniel L., David L. Peterson, Robert L. Smith (1994), “The AHP and Participatory Decision Making” in J. M. Power, M. Strome and Terry C. Daniel (ed.) Decision Support - 2001, Vol. 1: Proceedings of Combined events of $17^{\text {th }}$ Annual GIS Seminar and Resource Technology '94 Symposium, pp. 129-143.

Starkl, Markus, P. Raval, L Grassini, S. Grandi and T Donnelly (2003), "Sustainable Water Management - An Approach” in Brain Reed (ed.) Sustainable Environmental Sanitation and Water Services: Proceedings of $28^{\text {th }}$ WEDC Conference, Loughborough University, UK, pp. 206-209. 